\title{
Keeping it real: Exploring an interdisciplinary breaking bad news role-play as an integrative learning opportunity
}

\author{
Catherine Sweeney ${ }^{1}$, Eleanor O'Sullivan ${ }^{2}$, and Marian McCarthy ${ }^{3}$
}

\begin{abstract}
Palliative care is a complex area of healthcare best delivered by an interdisciplinary team approach. Breaking bad news is an inherent part of caring for people with life-limiting conditions. This study aims to explore an interdisciplinary breaking bad news role-play in a palliative care module. Participants were undergraduate medical and nursing students. Qualitative data from focus groups, student and facilitator feedback and a role-play recording were thematically analysed. The findings revealed that the role-play led to increased understanding of and changes in attitudes towards key palliative care principles, interdisciplinary teamwork, and communication of bad news. There was evidence of increased self-awareness. Findings suggest that the interdisciplinary breaking bad news role-play was a rich integrative learning experience valued by students.
\end{abstract}

Keywords: Interdisciplinary education, medical student, nursing student, breaking bad news, role-play, integrative learning

\section{Introduction}

Integrative learning is widely recognised as an essential component of modern third level education, (Higgs, Kilcommins \& Ryan, 2010; Huber \& Hutchings, 2004) providing students with concepts and frameworks that deepen their learning and assist in the development of key skills. Huber and Hutchings (2004) describe integrative learning as the making of connections between knowledge and skills from a variety of sources, the use of theory to inform practice, the ability to go beyond disciplinary boundaries in order to look at issues from a variety of perspectives and to look for solutions to real world problems. Interdisciplinary education is a commonly used means of providing integrative learning experiences (Carnegie Foundation, 2004).

The world of modern healthcare is constantly increasing in complexity as outlined by Plsek and Greenhalgh (2001). The Institute of Medicine (IOM, 2013) recommendations to address the issues of providing optimum healthcare at manageable cost include the need to develop systems that promote a culture of teamwork, communication and adaptability in the healthcare workforce, and to encourage patient and family engagement and empowerment. Hence the ability to think and work in an integrative manner is a vital aspect of modern healthcare.

Effective teamwork between disciplines is considered to be an essential component of modern high quality healthcare (Berwick, 2002; Legatt, 2007). Key organisations including the IOM, (2001), General Medical Council, (GMC, 2009) and the World Health Organisation (WHO, 2010) have highlighted the role of interdisciplinary education in preparing future

\footnotetext{
${ }_{1}^{1}$ Medical Education Unit, University College Cork, c.sweeney@uss.ie

2 Cork University Dental School \& Ionad Barra, University College Cork, eleanor.osullivan@ucc.ie

${ }^{3}$ Ionad Barra, The Teaching and Learning Centre, University College Cork, mmccarthy@ucc.ie
} 
healthcare professionals for interdisciplinary teamwork. While many modern undergraduate healthcare courses offer integrated curricula, the focus is usually on integrating the sciences (basic, behavioural and social), ethics and clinical practice. Interdisciplinary initiatives in undergraduate healthcare education remain the exception rather than the rule (Leggat, 2007).

In the contexts of education and clinical practice, the terms 'interdisciplinary' and 'interprofessional' are often used interchangeably. For the purpose of this article, the term interdisciplinary will usually be used in both contexts, while the original term used will be referred to in cited work. Interprofessional education has been defined as occurring "... when two or more professions learn with, from and about each other to improve collaboration and the quality of care" (Centre for the Advancement of Interprofessional Education, 2002). Jessup (2007) outlines the variety of terms used to describe healthcare practice where more than one discipline works in a team. Multidisciplinary teamwork is often used to describe healthcare practice where a number of disciplines work independently to care for a patient but interact formally to ensure that a range of care needs is covered. Practice involving a more integrated approach to care, demonstrated by a greater degree of interdependency between disciplines and individuals, with collaboration and sharing of expertise to achieve a common goal is increasingly referred to as interdisciplinary or interprofessional teamwork as outlined by Speck (2006).

\section{A. Palliative Care Education}

The WHO defines palliative care as "an approach that improves the quality of life of patients and their families facing the problems associated with life-threatening illness, through the prevention and relief of suffering by means of early identification and impeccable assessment and treatment of pain and other problems, physical, psychosocial and spiritual". The impact of a life-threatening illness on an individual and their family is multidimensional and hence palliative care provision is complex. Delivery of good quality palliative care requires clinicians who work collaboratively in interdisciplinary teams in an integrated manner. In addition, all healthcare professionals are highly likely to encounter individuals and families with palliative care needs and hence basic palliative care competencies are important for all at the point of qualification (GMC, 2009; Parry 2011; WHO, 1996). The European Association of Palliative Care (EAPC) recommendations on undergraduate medical curricula in palliative care (2013) and palliative nurse education (2004) identify key domains that need to be addressed to achieve these basic competencies. These include the principles of palliative care, symptom management, ethical and legal frameworks, patient and family perspectives, communication skills, self-awareness and teamwork. Hence palliative care education has the potential to provide a rich integrative teaching and learning experience. In particular, palliative care has been identified as a good setting for interprofessional undergraduate education by Wee et al., (2001), while Dando, d'Avray, Colman, Hoy, and Todd (2012) found that an interprofessional clinical placement in a hospice increased student awareness of professional roles.

Despite its apparent suitability, palliative care undergraduate education has not been well studied in the context of integrative learning or interdisciplinary education (Head et al., 2014). A recent mixed-methods study of palliative care education co-ordinators conducted in UK medical schools found that the main focus of most palliative care education programmes at undergraduate levels was assessment and management of common symptoms, while only $35 \%$ of programmes provided specific education on multidisciplinary teamwork (Gibbins, McCoubrie, Maher, Wee, \& Forbes, 2010). Dickinson (2006) reviewed teaching of end-of-life issues in US medical 
Sweeney, C., O'Sullivan, E. \& McCarthy, M.

schools and found that multidisciplinary teaching had increased from $59 \%$ in 1975 to $82 \%$ in 2005. Interestingly, neither of these national studies gathered data on interdisciplinary education.

\section{B. Breaking Bad News}

Buckman, (1984) defined breaking bad news (BBN), as delivering "any news that drastically and negatively alters the patient's view of her or his future"(p. 1597). The manner in which bad news is broken is significant for the individual receiving it and hence BBN training is widely considered to be an important facet of preparing undergraduates for clinical practice (GMC, 2009).

Usually BBN is taught by providing a theoretical framework such as the SPIKES model (Baile et al., 2000) and providing an opportunity for practice through role-play. Table 1 briefly outlines the SPIKES model.

Table 1

\begin{tabular}{ll}
\multicolumn{2}{l}{ Summary of SPIKES model for BBN } \\
\hline $\mathrm{S}$ & Activity \\
\hline $\mathrm{P}$ & Setting up the consultation \\
\hline $\mathrm{I}$ & Perception - assessing the patient's perception of their situation \\
\hline $\mathrm{K}$ & Invitation - obtaining the patient's invitation/permission \\
\hline $\mathrm{E}$ & Knowledge - giving the patient the knowledge/information \\
& $\begin{array}{l}\text { Emotion - acknowledging the patient's emotional response } \\
\text { Empathy - supporting the patient with empathy }\end{array}$ \\
\hline $\mathrm{S}$ & $\begin{array}{l}\text { Strategy for future care/management } \\
\text { Summarising the consultation }\end{array}$ \\
\hline
\end{tabular}

Role-play can be a powerful educational tool and is well suited to teaching and learning complex communication skills such as BBN. O'Sullivan (2011) stated, "the educational use of role-play has the potential to connect with people resulting in what we might call a felt understanding" (p. 536). Furthermore Sellers (2002) has asserted that role-play, "is capable of influencing participants' attitudes and emotions, whilst simultaneously promoting higher order cognitive skills" (p. 498). The action of role-play allows students to develop know-how and understanding. Hence amongst other things, role-play fosters changes in attitudes and perceptions and can facilitate modification of behavior (Bolton \& Heathcote, 1999). A wellconstructed palliative care BBN role-play requires participants to bring together knowledge of palliative care principles, understanding of patient perspectives, communication skills and teamwork. It therefore offers an ideal opportunity to assess integrative learning. BBN role-play can provide a practical opportunity for interdisciplinary education. However, little research has been undertaken in this area at undergraduate level. Wakefield, Cocksedge and Boggis (2006) qualitatively assessed an optional non-palliative care BBN course for medical and nursing students involving a BBN role-play scenario. Focus group interviews were used for post course evaluation. Themes emerging included the benefits of observing how other professions viewed problems, valuing other team members, and seeing other ways to do things. Our literature review did not find any studies of BBN teaching in an undergraduate interdisciplinary palliative care education context. 


\section{Module Context and Teaching Methods}

Palliative Care: An Interdisciplinary Approach (IP3008) is a 5-credit optional module offered to medical and nursing students in University College Cork (UCC). UCC runs two undergraduate medical programmes: a 5-year Direct Entry Medicine (DEM) course for secondary school leavers and a 4-year course Graduate Entry Medicine (GEM) course for students with a primary degree. Third year DEM, second year GEM students and final (fourth) year nursing students are offered enrolment on this module. Learning outcomes for IP3008 are outlined in Appendix A and module structure is summarised in Appendix B. Teaching consists of twenty hours of face-to-face teaching ( $10 \times 2$ hour sessions on consecutive weeks) and a 6hour online learning component on symptom assessment and management that complements three small group case-based learning sessions. Teachers come from a variety of disciplines and both clinical and academic backgrounds, including medicine, nursing, social work, physiotherapy and chaplaincy. Teaching is delivered in the education department of Marymount University Hospital and Hospice. In 2013/14 thirty-one students took the module (11 nursing, 10 DEM and 10 GEM students).

There were three student role-plays in the module, namely: (i) An initial non-clinical fun role-play, where students in groups were given a bag of props and asked to act out a scene from the owner's life. (ii) A relatively low stakes role-play of an interdisciplinary team meeting to organise a patient discharge. This was preceded by a fish-bowl role-play where students observed the enactment of an interdisciplinary palliative care team meeting by healthcare professionals. (iii) The BBN role-play, which acted as a culminating performance.

The BBN session started with an introductory 30-minute overview lecture introducing the SPIKES model of BBN. Students were then divided into three groups with a mix of medical and nursing students in each group. Each group was assigned a facilitator and an experienced patient role-player. The three facilitators were healthcare professionals with prior training in communication skills and experience of teaching BBN. Learning outcomes for the BBN session are outlined in Table 2 .

Table 2

Learning Outcomes for Breaking Bad News Session

Following this session students should be able to:

Identify the key components of BBN and apply these to a BBN role-play

Explain why BBN should be viewed as a process rather than an event

Explain why active listening is important in BBN

Argue the case for an interdisciplinary approach to BBN in a palliative care setting

Discuss the need to tailor BBN to the individual and their own unique circumstances

Students were asked to volunteer to take part in the role-play scenes; nursing students to play nursing roles and medical students to play medical roles. Table 3 outlines the structure used in the role-play.

The role-play was divided into 4 scenes reflecting real world stages in BBN. To maximise the number of students involved in the role-play, different students from the group took part in each scene, except for the final scene where the 3 nursing students from the previous scenes came together. In all scenes, at least 2 students were involved in the role-play. The 
remaining students acted as observers. A practising palliative care physician wrote the two-part scenario used for the role-play (Appendix C). All participants received part 1; part 2 was only given to the patient role-player, the facilitator and nursing students who volunteered to role-play (this second part contained 2 pieces of sensitive information that the patient had divulged to the nurse on a previous occasion). Observers were not given the scenario. The enactment of the roleplay required participants to integrate knowledge of palliative care principles, understanding of patient perspectives, communication skills and teamwork.

Table 3

\begin{tabular}{|c|c|c|c|}
\hline Scene & Title & Description & Participants \\
\hline 1 & $\begin{array}{l}\text { Pre- } \\
\text { planning } \\
\text { meeting }\end{array}$ & $\begin{array}{l}\text { Nurse and doctor meet to review the } \\
\text { case and plan BBN meeting with the } \\
\text { patient }\end{array}$ & $\begin{array}{l}\text { Nursing student } 1 \\
\text { Medical student } 1\end{array}$ \\
\hline 2 & $\begin{array}{l}\text { Meeting to } \\
\text { BBN }\end{array}$ & $\begin{array}{l}\text { Nurse and doctor meet the patient to } \\
\text { BBN }\end{array}$ & $\begin{array}{l}\text { Nursing student } 2 \\
\text { Medical student } 2 \\
\text { Patient role-player }\end{array}$ \\
\hline 3 & $\begin{array}{l}\text { De-briefing } \\
\text { meeting }\end{array}$ & $\begin{array}{l}\text { Nurse and doctor meet to debrief on } \\
\text { the BBN meeting }\end{array}$ & $\begin{array}{l}\text { Nursing student } 3 \\
\text { Medical student } 3\end{array}$ \\
\hline 4 & $\begin{array}{l}\text { Post BBN } \\
\text { support } \\
\text { meeting }\end{array}$ & $\begin{array}{l}\text { Nurse meets patient after BBN to } \\
\text { support the patient and address } \\
\text { patient concerns }\end{array}$ & $\begin{array}{l}\text { Nursing students } \\
1,2 \text { and } 3 \\
\text { Patient role-player }\end{array}$ \\
\hline
\end{tabular}

\section{Study Aims}

Our study aims were twofold:

1. To explore how an interprofessional BBN role-play can support integrative learning in a palliative care context.

2. To gain insights into students' learning and their experience of the role-play which would inform future teaching.

\section{Methods}

Ethical approval for this research project was obtained from Cork Research Ethics Committee of the Cork Teaching Hospitals and UCC School of Medicine Research Committee Ref ECM3(xx) 01/10/13.

Qualitative methods were considered most appropriate to explore the complexity of student learning in this area (Norton, 2009). An action research approach was taken as described by Metettal (2001) and outlined in Table 4. Schön (1995) has endorsed the use of action research to use practice to generate knowledge. Methods used for this investigation reflected on practice to uncover the evidence and development of student learning.

Qualitative data were obtained from the following sources:

a) Pre-module focus group student interviews to ascertain students' reasons for choosing the module and attitudes towards the interdisciplinary nature of the module (audio recordings and observer notes). 
b) Audio recording of one of the BBN role-play sessions and review of observer notes

c) Facilitator BBN feedback questionnaire (Appendix D)

d) Anonymous student BBN feedback questionnaire (Appendix E)

Table 4

Seven Steps of Classroom Action Research (Metettal, 2001)

\begin{tabular}{ll}
\hline Step & Action \\
\hline 1 & Identification of research question or problem \\
2 & Literature review \\
3 & Planning of research strategy \\
4 & Data gathering \\
5 & Data interpretation \\
6 & Take action based on findings \\
7 & Dissemination of findings \\
\hline
\end{tabular}

Two focus group interviews (one for medical students and one for nursing students) took place the week before the module started; each lasted approximately 45 minutes. Students attending these interviews provided written consent. Interviews were conducted by the first author and observed by a lecturer who teaches on the module. Interviews were tape-recorded and the observer made written notes. Initial focus group recordings were listened to, re-listened to and observer notes studied.

The first author observed one of the BBN sessions and took notes. The session was also tape-recorded. The recording was transcribed and studied along with the notes taken during the session.

The student BBN feedback questionnaire was distributed and collected at the final session of the module (1 week after the BBN session). Facilitator questionnaires were distributed 10 days after the BBN role-play session and returned shortly thereafter. Data were collated from the facilitator questionnaires. Thematic analysis of these data was undertaken manually by the first author using the method outlined by Norton (2009): data immersion, generation of categories, deletion of categories, merging of categories, checking of themes and linking of themes. Categories were reviewed and refined following discussion with co-investigators. The same method was used for analysis of the student questionnaires.

Early preliminary analysis of all data was undertaken and this informed further data collection e.g. student questionnaire feedback on the BBN session influenced the design of the facilitator questionnaire. 


\section{Results}

\section{A. Pre-module focus group interviews}

Ten students attended each of the 2 focus group interviews. Analysis of Focus Group interviews (recordings and observer notes) revealed that none of the students had chosen the module for its interdisciplinary nature; in fact, many were surprised that it was interdisciplinary (despite the fact that this was stated in the title and detail of the module descriptor). Notwithstanding this, students seemed to view the opportunity to learn with students from another discipline positively.

Both groups of students reported that they chose the module because of perceived educational needs and for some an interest in pursuing a career in a related specialty. Nursing students perceived this to be a rewarding area of work. Some medical students reported an interest based on prior personal or professional experience with palliative care.

Table 5

Summarises demographics of students enrolled on the module

\begin{tabular}{lll}
\hline & Nursing Students & Medical Students \\
\hline Number & 11 & 20 \\
Sex Female & 10 & 11 \\
$\quad$ Male & 1 & 9 \\
Median Age (years) & 22.5 & 24 \\
Age Range & $20-50$ & $20-37$ \\
\hline
\end{tabular}

\section{$B$. Audio recording of a $B B N$ role-play session and observer notes}

The role-play session commenced with the purpose (to give students a chance to practice in a supportive environment) and structure of the session being explained to the group. Students were asked to volunteer for role-play (3 nursing and 3 medical students). The ground rules and scene were set. Students were advised they could halt the role-play at any time if they felt they were in difficulty and that the facilitator would pause and rewind the role-play at times.

The session continued with the first scene. The two students discussed the case but required guidance to focus on what information they would be divulging and to get to the point where they felt would be able to act as a team. Some of the sensitive information that only the nurse knew was divulged to the doctor, but not all. In the second scene students followed the SPIKES model to break the bad news but struggled at times with coordinating their efforts as a team. The facilitator provided guidance at these points on how to work as a team, recognize the limits of one's role and defer to a colleague.

The group explored the challenges of dealing with the patient's emotions and their own reaction to these. Throughout the role-play Student efforts were affirmed and parts of scenes were rewound and replayed to allow students to experience the effects of different actions. The later scenes were played with students demonstrating increased understanding of teamwork as they progressed by demonstrating knowledge of the limits of their role, handing over to their colleague when appropriate and making sure important aspects such as support for the patient's 
family were covered. The ethical issues around disclosure of sensitive information were also teased out.

The students who were observing were engaged and provided insightful feedback throughout the session. Finally the facilitator led a debriefing of the entire session involving all participants and observers in which the emotional impact of the session and the importance of self-care were discussed.

\section{Facilitator feedback on BBN Role-play}

Feedback was obtained from the 3 facilitators of the role-play groups. Facilitator feedback identified three main themes, namely: role-play as a teaching method, student performance in areas such as palliative care knowledge, teamwork and communication, and implications for future teaching.

Role-Play as a Teaching Method. Role-play was considered to be the best way to teach students the skills needed to break bad news. One facilitator stated, "There is no better way than to sit in the hot seat and really experience what it could be like in the real world ... Very good for developing problem-solving skills as well as critical thinking skills ..." (Facilitator 1). Another added, "Properly conducted and managed experiential learning in the style modelled here is not just a good way to teach breaking bad news, it is the only way." (Facilitator 3).

Students gained practical experience of dealing with a realistic complex communication challenge in an interdisciplinary context. The role-play was described as "disarmingly realistic ... excellent experiential tool" (Facilitator 3).

A high level of student engagement with the role-play scenarios was apparent from all facilitators' feedback. Students engaged with both the role-play process and with the case as evidenced by appropriate verbal and non-verbal responses to the patient and her predicament: "It engaged all students and incorporated both the medical and nursing role" (Facilitator 2). Facilitator 3 was reportedly surprised by "The honesty of the students and their willingness to trust the facilitator and the process. I suspect that this was facilitated by the relationships and trust that were established in the earlier sessions.".

Student Performance. Through their performances, students demonstrated an awareness of palliative care principles and ethical issues taught earlier in the module and elsewhere in their undergraduate courses. These included holistic patient care, the concept of total pain, the focus on quality of life and the family unit.

The complexity of balancing confidentiality versus divulging information that was important for the team was handled well by some nursing students. "They were sensitive to divulging this information and only did so if they felt it impacted on the decisions being made on the patient." (Facilitator 1). However, this was not the case for all students as one facilitator commented, "In our group the nurse divulged none of this sensitive information at the planning meeting. I think that it really only emerged with some prompting toward the very end of the exercise." (Facilitator 3). In this group this presented a teaching and learning opportunity and a discussion was facilitated around the needs of team members for information and how to seek permission from a patient to disclose sensitive material.

Students initially struggled with the interdisciplinary team aspects of the role-play, for example they didn't refer to their colleague for aspects where they had more expertise. This was attributed to lack of experience of working in an interdisciplinary team. As the session progressed, students appeared to develop a better understanding of how to work in a team and 
the advantages and challenges of having the two disciplines involved and working together. One facilitator commented, "Understandably, when one considers the lack of experience amongst the group, the meeting was largely focused on the mechanics of telling the patient the news. In later scenarios, there was a greater sense of working together but given the relative inexperience of the group, I would not have expected any other outcome." (Facilitator 3). Another added that, "Students eventually realized that the different disciplines cannot work in isolation from each other - it has to be a team approach with the patient and their family" (Facilitator 1).

Giving difficult facts to the patient while maintaining hope and responding to the patient's emotions were major challenges for the students. One facilitator reported, "They were very uncomfortable with the notion of upsetting or distressing the patient..." (Facilitator 3). Despite these challenges students appeared to appreciate the opportunity to practice BBN, "There seemed to be relief on students' faces, as if that was their first one done!" (Facilitator 2), ".... and as difficult as it was, appeared to appreciate the experience." (Facilitator 1).

Implications and Recommendations for Future Teaching and Learning. There were two main recommendations:

- All facilitators agreed that more practice of role-play to develop skills and improve performance was very important.

- Students need to see performances of good communication in BBN either by being present to see it first hand, "appropriate 'modelling' in the clinical environment as students or young post-graduates" (Facilitator 3) or by watching recordings of experts.

\section{Student Feedback on BBN Role-play}

Twenty-four students completed the anonymous written feedback questionnaire on the BBN session. Analysis revealed three main themes: changes in knowledge, skills and attitudes, the experience and emotional impact of the BBN session, and $\mathrm{BBN}$ role-play as an educational method.

Changes in knowledge, skills and attitudes. Student responses provide evidence that the BBN role-play brought together and reinforced prior learning. One student commented, "It brought every part of the module together. It's as if every week built up to it" (Student 15).

A number of subthemes were identified relating to the impact of the session on the students' knowledge, skills and attitudes relating to their future roles as healthcare professionals. Evidence emerging from the analysis included understanding in the areas of palliative care, communication skills and teamwork.

Understanding of Palliative Care. Students gained an appreciation of the importance of holistic patient and family care and of seeing things from the patient's perspective, understanding non-physical dimensions of serious illness and offering appropriate ongoing support of these dimensions in an integrated manner. Many commented on how the role-play had helped them to see the impact of $\mathrm{BBN}$ on those receiving it. Students frequently indicated increased understanding of 'Total Pain', which relates suffering in a broad sense. One student stated, "The topic of 'Total Pain' really came into action in the role-play. I realized there's so much more than just the physical aspects of cancer. It's important to be aware of the emotional, spiritual and social aspects of pain" (Student 13). There was evidence that students appreciated that palliative care addresses all these dimensions and focuses on maximizing quality of life, and that it is not just about care in the final days of life. 
Communication. Analysis revealed that students gained greater understanding of the need for good communication and how to do it. One student reported that he now understood "how 'emotions' of patient and Dr may be handled.... How to inform the patient of bad news and not overload them, rather, give them time to digest the information" (Student 18). Many commented that they had gained knowledge and learned practical skills that would help them in their future careers as healthcare professionals. The structured approach using the SPIKES model received positive feedback. One student stated, "It emphasised the need to have a structured approach not just launching into a conversation, a great deal of planning is necessary...." (Student 18). Again there was evidence of attitudinal change; one student commented that the role-play had, "Taught me active listening and how you can be there for someone without saying anything at all" (Student 14). There was an acknowledgement that BBN is a process rather than a single event.

Interdisciplinary Teamwork. Areas of interdisciplinary teamwork where students had gained increased understanding included, the need for and benefits of teamwork, roles within the team, and practical issues in team working.

The broader perspective provided by a team approach and the benefits of this to the patient and the family were highlighted. A student reported that the role-play had helped her "... to realise how valuable the team members are and that each member comes with a slightly different view of the patient because of the different interacting roles and all these view points are important in helping the patient" (Student 4).

In addition to the advantages of an interdisciplinary team approach for the patient and their family, there was evidence that students' perceived benefits for the healthcare professionals involved in terms of the support team members can give to each other and learning from other disciplines.

The experience and emotional impact of $B B N$ on the students. Many students indicated that they found BBN difficult. Some mentioned the challenges in maintaining hope for patients and families. Other students mentioned the emotional impact of BBN, "How emotionally involved everyone was, even those just watching. Hours later we were still affected by it" (Student 19). Students appeared to have become more aware of the range of skills required of healthcare professionals. One student stated, "I realise...the broad range of skills needed to be a successful healthcare professional in the area" (Student 11).

The feedback indicated that students had been surprised at how difficult it was to BBN. The experience had prompted self-reflection and for some awareness of their learning needs. One student commented that he was surprised by "how drained and inadequate I felt when delivering the bad news" (Student 5), while another stated, "I know my shortfalls now after doing it and can go on and try to improve on these. I gained confidence with what I am good at with respect to BBN" (Student 11).

However despite the difficulties involved, many commented on positive aspects of the experience. Students appeared to have valued the opportunity to practice in a controlled environment as preparation for the day when they would be doing this in the real world. A sense of accomplishment and relief was expressed by a number of students with one stating "I thought it would be very sad + upsetting. I found it tough but enjoyable and therapeutic" (Student 14).

$B B N$ role-play as an educational tool. Many students referred to the role-play in terms of how real they found it and how it engaged them. The sense of reality brought by role-playing appears to have made a deep emotional impact. This often surprised students. One student stated, "How I imagined this case so strongly that it seemed real \& made me feel a range of emotions throughout..." (Student 18). Students appreciated role-play as a teaching method, "I think the 
role-play was an excellent method of teaching" (Student 14). The provision of theory and practice on the same day appears to have been well received.

\section{Discussion}

This study provides evidence that a palliative care BBN role-play can offer a rich integrative learning experience that is highly valued by students. Evidence from the role-play recording, facilitator and student feedback supports the assertion that integrative learning occurred. Students' feedback indicates increased understanding in key areas of relevance to palliative care, including the need for holistic care of patients and families, interdisciplinary teamwork, how to communicate difficult information and professional responsibilities. Evidence from facilitator feedback and the audio recording of the BBN session also support this. The finding that the session prompted student self-reflection and self-awareness is further evidence of integrative learning.

According to the Association of American Colleges and Universities and the Carnegie Foundation (2004), in order to provide integrative learning students must be supported to "put the pieces together and develop habits of the mind that help them to make informed judgments". Huber and Hutchings, (2004) have asserted that working on real-world problems that highlight the need to consider different perspectives and challenge students to make connections from disparate areas facilitates integrative learning. A number of factors contributed to the integrative learning potential of the BBN session. Firstly palliative care is a complex field where an integrated approach is needed. Hence the context of the BBN session was an important factor. In addition, BBN in itself is a complex communication challenge and using role-play as a teaching method highlights to students the difficulties encountered in its performance. The interdisciplinary nature of the student group also provided a very significant integrative learning opportunity. The carefully constructed scenario which was designed to bring out disciplinary perspectives, ethical aspects and the multidimensional nature of issues faced by palliative care patients provided a vital scaffold for the teaching and learning in the session. In addition, the real-life authenticity of the process of BBN (planning, delivering, supporting and debriefing) added a further important dimension. Both students and facilitators commented on how real the role-play seemed. Analysis of data from facilitator and student feedback and the audio recording of the role-play indicate that there was a high level of emotional engagement with the session, which in itself can make for a potent integrative learning experience according to Huber \& Hutchings (2004).

This research has a number of limitations. Firstly, the qualitative approach taken has implications in terms of generalizability. Secondly only two disciplines were involved. It would be valuable to involve students from other key disciplines such as social work to broaden the interdisciplinary aspect. Unfortunately due to timetabling issues we are not currently in a position to offer the module to students from other disciplines. Another limitation is the elective nature of the module; as the students self-select there is a possibility that those who participated in this study are more integrative learners than their peers. However, as none of those interviewed chose it because of its interdisciplinary nature it appears this was not a motivating factor for students' choice. This research was conducted during and in the immediate aftermath of the BBN session. It is not possible to predict what the long-term impact will be on students and this is an important area for further study. In order to develop as integrative thinkers, students should be offered multiple integrative learning experiences throughout the course of 
their studies (Association of American Colleges and Universities \& The Carnegie Foundation, 2004). This is only one such experience for a limited number of students. It is important to note that the BBN session was the $9^{\text {th }}$ of 10 sessions in the module and learning from other aspects of the module will have influenced student performance and learning in the BBN role-play.

Our study found that students developed awareness of the broader view offered by an interdisciplinary team approach and appreciated the input of the other discipline in terms of the support it gave them and the potential it provided to improve patient care and the opportunity it provided to learn. The work on BBN role-play by Wakefield, Cocksedge \& Boggis (2006) reported similar findings in relation to interdisciplinary teamwork. In addition, in the current study students reported having a clearer understanding of the roles of the disciplines in BBN and how to work with each other in a team. Students also reported learning from another discipline. In studies of education in BBN, few look at outcomes apart from students' or clinicians' perceptions of competence, satisfaction with teaching methods or measurement of communication skills. This study has broadened this perspective and found evidence that with appropriate supports, and in an interdisciplinary palliative care setting, the teaching of BBN has the potential to enhance student understanding of the practicalities of interdisciplinary teamwork and the benefits of this approach for patients, families and team members.

Huber and Hutchings (2004) describe self-awareness as an important aspect of integrative learning. We found evidence of increased self-awareness after the intervention. Some students reported that they felt better prepared to meet the communication challenge posed by BBN, while others indicated that they became more aware of their deficits and learning needs in this regard. These findings are also supported by those of a recent study by Layat Burn, Hurst, Ummel, Cerutti, and Baroffio (2014), who found evidence of increased self-awareness on follow up of students after a BBN teaching intervention that involved role-play. Hence further evidence is provided of the integrative learning potential of $\mathrm{BBN}$ role-play. It is the experience of facilitators that every year in IP3008 the BBN session also increases student awareness of the importance of self-care and this topic is covered in the debriefing at the end of the role-play and again in the final session of the module.

Learning about key principles of palliative care during the BBN session is supported by student feedback, including the importance of holistic care, family involvement, principles of non-abandonment and that palliative care is not end of life care. There was also evidence of increased understanding of how to communicate in the challenging circumstances of BBN.

Role-play is commonly used to teach communication skills in undergraduate and postgraduate healthcare education (Nestel \& Tierney, 2007), and in particular as a method to teach BBN (Baile et al., 1999; Liénard et al., 2010; Park et al., 2010). The appropriateness of role-play as a teaching method for $\mathrm{BBN}$ teaching emerged strongly from both student and facilitator feedback.

The design of our role-play, both in terms of structure and content was firmly based in real life, and appears to have been successful in meeting learning outcomes and facilitating integrative learning. There is a considerable evidence that the role-play changed students' attitudes and perceptions and prompted "a type of knowing which results in people taking a personal interest in issues and wanting to effect change" (O'Sullivan, 2011, p. 536). Our research provides evidence of the potential for role-play in education to enhance self-awareness.

This study provides further evidence that students value and are willing to engage with properly supported role-play. The level of student engagement with, and contribution to the BBN exercise surprised experienced facilitators. These findings mirror those of Nestel and Tierney 
(2007) who found evidence that students value the experience if provided with appropriate preparation and roles, opportunities to observe and discuss, and structured feedback. However, students do not always view role-play positively as an educational method. Lack of familiarity and understanding of the technique and previous bad experiences of role-play can provoke anxiety and unwillingness to participate (Nestel \& Tierney, 2007; Stevenson \& Sander, 2002). Multiple factors may have contributed to our students' positive attitudes. It is important to note that the BBN role-play was the third role-play in the module and was by far the most complex and challenging. The module design deliberately built up to this by exposing the students to a number of role-plays over the preceding weeks to prepare them for the BBN session. In addition, the prior presentation of the SPIKES model for BBN, the structure of the role-play itself and the inclusion of structured feedback are all likely to have provided a supportive environment where students were willing to participate.

Our finding that students struggled with teamwork aspects in the role-play is an important one. With the current focus on the need for interdisciplinary teamwork in healthcare, the question of whether we are adequately preparing graduates for this important aspect of practice is raised and should be the focus of future research.

Schön (1995) stated, "Perhaps there is an epistemology of practice that takes fuller account of the competence practitioners sometimes display in situations of uncertainty, complexity, uniqueness and conflict" (p. 29). Evidence from our study suggests that a wellconstructed and supported interdisciplinary BBN role-play can be an effective teaching tool to support student learning and skill development in difficult communication skills and interdisciplinary teamwork.

\section{Conclusion}

A well-designed interdisciplinary role-play of $\mathrm{BBN}$ based on real life practice allows for an authentic hands-on integrative teaching and learning encounter that is highly valued by students. Consideration should be given to increasing the number of such experiences in undergraduate healthcare education.

\section{Acknowledgements}

The authors wish to acknowledge the following colleagues who enthusiastically give of their expertise and their time to teach on IP3008. Ms Ann McAuliffe, Prof. Tony O'Brien, Dr Marie Murphy, Dr Mags Clifford, Dr Bridie McCarthy. Thanks are also due to the staff of Marymount University Hospice Cork. This module was established with the support of a development grant from the Irish Hospice Foundation.

\section{Appendices}

Appendix A: Learning Outcomes for IP3008

On successful completion of this module, students should be able to:

Discuss the main principles of palliative care

Outline a basic approach to assess and manage common symptoms

experienced by palliative care patients

Describe the fundamentals of ethics in palliative care 
Identify the settings in which specialist palliative care services are delivered and know how to access these services

Describe the importance of holistic, collaborative, individualized care of patients and their families

Identify the key components of breaking bad news

Compare the palliative care approach with the traditional medical model of care

Argue the case for early referral to palliative care

Discuss the strengths, opportunities and challenges of interdisciplinary education and healthcare practice

Appendix B: Overview of IP3008 Teaching Sessions

\begin{tabular}{|l|l|}
\hline IP3008 2013/14 & Topic \\
\hline Session (date) & $\begin{array}{l}\text { Overview of module } \\
\text { Anna's story: DVD and discussion } \\
\text { Role-play: team building exercise } \\
\text { Optional tour of Hospice }\end{array}$ \\
\hline (Sept 18) & $\begin{array}{l}\text { Principles of Palliative care Lecture } \\
\text { Inter disciplinary teamwork - Stereotyping exercise 1 hour }\end{array}$ \\
\hline 3 (Oct 2) & $\begin{array}{l}\text { Teamwork Lecture } \\
\text { Fishbowl role-play: interdisciplinary team act out a team meeting } \\
\text { for students } \\
\text { Role-play students play interdisciplinary team at a patient discharge } \\
\text { planning meeting }\end{array}$ \\
\hline 4 (Oct 9) & Case Study in small groups part 1 \\
\hline $5($ Oct 16) & Care of Dying Patient and their Family \\
\hline $6($ Oct 23) & Case Study in small groups part 2 \\
\hline 7 (Oct 30) & $\begin{array}{l}\text { Total Pain Lecture } \\
\text { Real Patient Interview }\end{array}$ \\
\hline 8 (Nov 6) & Case Study in small groups part 3 \\
\hline 9 (Nov 13) & BBN/Communication Workshop \\
\hline 10 (Nov 20) & $\begin{array}{l}\text { Self Care Lecture } \\
\text { Module debriefing \& feedback }\end{array}$ \\
\hline
\end{tabular}

Appendix C: Breaking Bad News Scenario

Part 1: All participants in role-play and facilitator

Mary is a 43-year-old married lady with advanced malignant melanoma. She is currently an inpatient on the oncology ward. Her disease dates back over three years and she has undergone multiple lines of therapy. Recent investigations confirm extensive and progressive burden of disease affecting lungs, liver and lymph nodes. Currently, Mary is profoundly fatigued and requires assistance with all ADLs. She is deeply jaundiced but denies any pain. She is oxygen dependent. Her prognosis is limited to a few days or at best, perhaps a few short weeks.

Mary is married to Peter and they have three children - Jack (12), Emily (9) and Becky (5). All three children attend the local national school. Peter is a secondary school teacher and Mary had previously worked as a nurse in a general practice setting. She has not worked as a nurse since 
her diagnosis. They have excellent support from Mary's parents (Tom \& Betty) who are actively involved in the care of the children. Also, Mary's only sister Claire has recently returned from Australia for an 'extended holiday'. Peter has no siblings in Ireland and both of his parents have died in recent years.

Mary coped with her illness by 'being positive'. She actively researched her disease and all treatment options. She views 'negativity' as a failing and despite her massive burden of disease, continues to express a desire for more treatment - 'what have I got to lose?' Peter reports that the children are manifesting signs of distress with frequent illness (tummy pain) and the youngest Becky (5) has developed nocturnal enuresis. Peter has separately asked for some help and advice re preparing the children.

Today's meeting was arranged to discuss the situation and to advise Mary that there are no further treatment options other than pain and symptom management. Mary declined the suggestion that Peter should be in attendance - 'He's too busy with work and the children - I don't want to burden him.' Mary has indicated that she would like to meet with the oncology doctor and the nurse who has looked after her since her first diagnosis.

\section{Part 2: Nurse, role player and facilitator only}

You (the nurse) have cared for Mary since her initial diagnosis. You feel very close to her and she has confided a lot in you over the years. She trusts you.

You are very acutely aware of a discussion that took place nine months ago when Mary was very unwell with overwhelming sepsis. It was not at all clear if she would survive. You were nursing her at the time and she spoke with you about her fears of dying and of leaving Peter and the children. She reported that Peter is not a natural parent and that he has little patience with the children. She volunteered that her parents know of his shortcomings and try to help whenever they can.

She also volunteered that her marriage went through a very rocky phase around the time of her diagnosis. Peter had at least one affair that he acknowledged and Mary was frightened that he might set up a relationship with this woman following her death. Mary does not like the woman and would hate for her to be caring for her children. She has not discussed this with her parents or sister, as she does not want to turn them against Peter.

She is also struggling with the 'why me' question and volunteered that as a teenager, she had impulsively once made a half-hearted attempt on her own life. She wondered if her disease was a punishment from God for acting in this way.

More recently, Mary reported to you that she feels the children are aware that she is ill but they have no idea that she might die. They bring in drawings depicting their Mum as 'superman' or as a Queen. Mary feels guilty that she has not been available to her children as a mother should over the past three years - 'what good am I to my children - I can't do any of the normal things. I think that they might be better off without me. I'm not a normal mother or wife. I don't really blame Peter for the affair - any man would do the same.'

\section{Appendix D: Facilitator Feedback Questionnaire on BBN Role-play}

1. As a facilitator how effective did you find the structure of the scenario to engage students in the role-plays?

2. How did students demonstrate their understanding (or lack of understanding) of how to work as an interdisciplinary team? 
3. In what ways, if any, did the nurse demonstrate understanding of teamwork in the divulging of information that only he/she knew about the patient's circumstances to the doctor?

4. In what ways, if any, did the students demonstrate an understanding of fundamental palliative care principles?

5. Regarding the Role-plays:

a) In what ways were you satisfied or dissatisfied with how students played out the Breaking of Bad News?

b) What challenges did you notice for students in their breaking of bad news?

c) What do we learn from these role-plays about the challenges students face in breaking bad news?

d) What are the implications of this learning for future education?

6. Comment on how you found the teamwork aspect of the role-plays?

7. Student feedback indicates that they really value and like the session but that they find BBN difficult. Do you have any ideas on how we could support students further?

8. What surprised you?

Appendix E. Student BBN Role Play Feedback Questionnaire

What impact did the role-play have on your understanding of breaking bad news?

What impact did the role-play have on your understanding of palliative care?

What impact did the role-play have on your understanding of interdisciplinary teamwork?

What surprised you?

\section{References}

Association of American Colleges and Universities and The Carnegie Foundation. (2004). A Statement on Integrative Learning. Retrieved from http://www.evergreen.edu/washingtoncenter/docs/intlearning/statementintlearning.pdf

Baile, W. F., Kudelka, A. P, Beale, E.A., Glober, G. A., Myers, E.G., Greisinger, A. J., ... Lenzi, R. (1999). Communication skills training in oncology. Description and preliminary outcomes of workshops on breaking bad news and managing patient reactions to illness. Cancer, 86(5), 887897. doi: 10.1002/(SICI)1097-0142(19990901)86:5<887::AID-CNCR27>3.0.CO;2-X

Baile, W.F., Buckman, R., Lenzi, R., Glober, G., Beale, E. A. \& Kudelka, A. P. (2000). SPIKESA six-step protocol for delivering bad news: application to the patient with cancer. Oncologist, 5(4), 302-311. doi: 10.1634/theoncologist.5-4-302

Berwick, D. M. (2002). A user's manual for the IOM's 'Quality Chasm' report. Health Affairs, 21, 80-90. doi: 10.1377/hlthaff.21.3.80

Bolton, G. M., \& Heathcote, D. (1999). So you want to use role-play?: A new approach in how to plan. Stoke-on-Trent: Trentham.

Buckman, R. (1984) Breaking bad news: why is it so difficult? British Medical Journal, 288, 1597-1599. doi: 10.1136/bmj.288.6430.1597 
Sweeney, C., O'Sullivan, E. \& McCarthy, M.

Centre for the Advancement of Interprofessional Education. (2002). Defining IPE. Retrieved from http://caipe.org.uk/about-us/defining-ipe/

Carnegie Foundation. (2004). What is Integrative Learning? Carnegie Foundation Retrieved from http://gallery.carnegiefoundation.org/ilp/what-is-ILP.htm

Dando, N., d'Avray, L., Colman, J., Hoy, A., \& Todd, J. (2012). Evaluation of an interprofessional practice placement in a UK in-patient palliative care unit. Palliative Medicine, 26(2), 178-184. doi: 10.1177/0269216311400479

Dickinson. GE. (2006). Teaching end-of-life issues in US medical schools: 1975 to 2005. American Journal of Hospice and Palliative Care, 23(3), 197-204. doi: $10.1177 / 1049909106289066$

European Association for Palliative Care. (2004). A guide for the development of palliative nurse education In Europe. Palliative Nurse Education: Report of the EAPC Task Force 20. Retrieved http://www.eapcnet.eu/LinkClick.aspx?fileticket=e9JnEa7YZDM\%3d

European Association for Palliative Care. (2013). Recommendations of the European Association for palliative care for the development of undergraduate curricula for palliative medicine in European medical schools. Retrieved from http://www.palliatief.n1/Portals/31/publicaties/201311-25EAPC_UndergraduateCurriculumUpdate2013.pdf

General Medical Council. (2009). Tomorrows doctors: Outcomes and standards for medical education. Retrieved from http://www.gmcuk.org/education/undergraduate/tomorrows doctors 2009.asp

Gibbins, J., McCoubrie, R., Maher, J., Wee, B., \& Forbes, K. (2010). Recognizing that it is part and parcel of what they do: teaching palliative care to medical students in the UK. Palliative Medicine, 24(2), 299-305. doi: 10.1177/0269216309356029

Head, B. A., Schapmire, T., Hermann, C., Earnshaw, L., Faul, A., Jones, C., Shaw, M. A., ... Pfeifer, M. (2014). The Interdisciplinary Curriculum for Oncology Palliative Care Education (iCOPE): Meeting the challenge of interprofessional education. Journal of Palliative Medicine 17(10), 1107-1114. doi: 10.1089/jpm.2014.0070.

Higgs, B., Kilcommins, S., \& Ryan, T. (2010). Making connections: Intentional teaching for integrative learning. Cork: NAIRTL.

Huber, M. T., \& Hutchings, P. (2004). Integrative learning: Mapping the terrain. Washington, DC: Association of American Colleges and Universities.

Institute of Medicine. (2013). Best care at lower cost: The path to continuously learning health care in America. Washington, DC: The National Academies Press. 
Sweeney, C., O'Sullivan, E. \& McCarthy, M.

Jessup, R. L. (2007). Interdisciplinary versus multidisciplinary care teams: Do we know the difference. Australian Health Review, 31(3), 330-331. doi:10.1071/AH070330

Legatt, S. (2007). Effective healthcare teams require effective team members: Defining teamwork competencies. BMC Health Services Research 7(17). doi: 10.1186/1472-6963-7-17

Layat Burn, C., Hurst, S. A., Ummel, M., Cerutti, B., \& Baroffio, A. (2014). Telling the truth: Medical students' progress with an ethical skill. Medical Teacher, 36(3), 251-259. doi: 10.3109/0142159X.2013.853118.

Liénard, A., Merckaert, I., Libert, Y., Bragard, I., Delvaux, N., Etienne, A. M., ... Razavi, D. (2010). Is it possible to improve residents breaking bad news skills? A randomised study assessing the efficacy of a communication skills training program. British Journal of Cancer, 103(2), 171-177. doi: 10.1038/sj.bjc.6605749

Metettal, G. (2002). The what, why and how of classroom action research. The Journal of the Scholarship of Teaching and Learning, 2(1) 7-13.

Nestel, D., \& Tierney, T. (2007). Role-play for medical students learning about communication: Guidelines for maximising benefits. BMC Medical Education, 7(3). doi:10.1186/1472-6920-7-3

Norton, L.S. (2009). Action Research in Teaching and Learning: A practical guide to conducting pedagogical research in universities. London: Routledge.

O’Sullivan, C. (2011) Role-Playing. In L. Cohen, L. Manion and K. Morrison (Eds.), Research methods in education ,7th edition (pp. 536-554) London: Routledge.

Park, I., Gupta, A., Mandani, K., Haubner, L., \& Peckler, B. (2010). Breaking bad news education for emergency medicine residents: A novel training module using simulation with the SPIKES protocol. Journal of Emergency Trauma Shock, 3(4), 385-388. doi: 10.4103/09742700.70760

Parry, M. (2011). Student nurses' experience of their first death in clinical practice. International Journal of Palliative Nursing, 17(9), 446-51. doi: 10.12968/ijpn.2011.17.9.448

Plsek, P. E., \& Greenhalgh, T. (2001). The challenge of complexity in health care. British Medical Journal, 323(7313), 625-628. doi: 10.1136/bmj.323.7313.625

Schön, D. A. (1995). Knowing in action: The new scholarship requires a new epistemology. Change. Nov/Dec 27-34. doi: 10.1080/00091383.1995.10544673

Sellers, S. C. (2002). Testing theory through teaching theatrics. Journal of Nursing Education, 41, 498-50.

Speck, P. (2006). Teamwork in palliative care: Fulfilling or frustrating. New York: Oxford University Press. doi: 10.1093/acprof:oso/9780198567745.001.0001 
Stevenson, K., \& Sander, P. (2002). Medical students are from Mars-business and psychology students are from Venus-University teachers are from Pluto? Medical Teacher, 24(1), 27-31. doi:10.1080/00034980120103441

Wakefield, A., Cocksedge, S., \&Boggis, C. (2006). Breaking bad news: qualitative evaluation of an interprofessional learning opportunity. Medical Teacher, 28(1), 53-8. doi:

$10.1080 / 01421590500312805$

Wee, B., Hillier, R., Coles, C., Mountford, B., Sheldon, F., \& Turner, P. (2001). Palliative care: a suitable setting for undergraduate interprofessional education. Palliative Medicine, 15(6), 48792. doi: 10.1191/026921601682553978

World Health Organisation. Definition of palliative care. World Health Organisation. Retrieved from http://www.who.int/cancer/palliative/definition/en/

World Health Organisation. (1996). Physician education In palliative medicine: A vehicle to change the culture of pain management. Retrieved from http://www.whocancerpain.wisc.edu/?q=node/275

World Health Organisation. (2010). Framework for action on interprofessional education \& collaborative practice. Geneva. Retrieved from http://www.who.int/hrh/nursing midwifery/en/ 